\title{
The influence of affective factors on time perception
}

\author{
ALESSANDRO ANGRILI, PAOLO CHERUBINI, ANTONELLA PAVESE, \\ and SARA MANFREDINI \\ University of Padua, Padua, Italy
}

\begin{abstract}
Several studies have suggested that both affective valence and arousal affect the perception of time. However, in previous experiments, the two affective dimensions have not been systematically controlled. In this study, standardized photographic slides rated for emotional valence and arousal were projected to two groups of subjects for 2,4 , and $6 \mathrm{sec}$. One group of subjects estimated the projection duration on an analog scale, whereas the second group of subjects reproduced the intervals by pushing a button. Heart rate and skin conductance responses were also recorded during stimulus presentation as indices of attention and arousal. Time estimation results showed neither a main effect of valence nor a main effect of arousal. A highly significant valence $X$ arousal interaction affected duration judgments. For low-arousal stimuli, the duration of negative slides was judged relatively shorter than the duration of positive slides. For high-arousal stimuli, the duration of negative slides was judged longer than the duration of positive slides. The same interaction pattern was observed across judgment modalities. These results are interpreted in terms of a model of action tendency, in which the level of arousal controls two different motivational mechanisms, one emotional and the other attentional.
\end{abstract}

In everyday life, human beings are continually engaged in emotionally driven behaviors. Such behaviors are so highly pervasive that the recent psychological literature has pointed out the centrality of emotional factors in cognitive processes such as learning a second language (Schumann, 1990, 1994). Damasio (1994) has recently documented a remarkable body of neuropsychological evidence supporting the assumption that emotions are involved in most, if not all, cognitive processes.

Although an increasing number of studies have investigated the role of emotions in cognitive activity, only a limited number of studies have analyzed the relationship between emotional states and estimation of time durations. Furthermore, these studies have typically yielded inconclusive results regarding the precise nature of the relationship between emotions and time perception. These inconsistent findings may originate from the use of nonstandardized emotional manipulations that make the quantification and replication of the results rather problematic.

A leading theoretical approach in the current literature involves the dimensional analysis of emotions. Dimensional theories of emotion differ from basic emotions theories (Argyle, 1975; Chance, 1980; Plutchik, 1962) in that they do not classify emotions on the basis of the presence or absence of independent and specific emotional states (e.g., fear, anger, or joy). Instead, they assume that emotions can be represented in a multidimensional space

We wish to thank G. B. Vicario, P. J. Lang, L. Stegagno, D. Palomba, P. Bressan, R. Mucha, and L. Krueger (associate editor), and the referees for their helpful suggestions and comments. Correspondence should be addressed to Alessandro Angrilli, Antonella Pavese, or Paolo Cherubini, Dipartimento di Psicologia Generale, Università di Padova, v. Venezia, 8-35131 Padova, Italy (e-mail: angrilli@psico.unipd.it). defined by a number of factors varying along a continuum. According to psychophysiological studies that used standardized emotional material (Greenwald, Cook, \& Lang, 1989; Lang, 1984; Lang, Greenwald, Bradley, \& Hamm, 1993; Tellegen, 1985), two factors account for most of the variance in emotional judgments: affective valence and arousal. ${ }^{1}$ These two dimensions correspond to the behavioral dimensions of direction (approach or avoidance) and intensity (i.e., mobilization) advocated by a biphasic organization of emotional responses (Lang, Bradley, \& Cuthbert, 1990).

In the present study, we tested the hypothesis that emotional states induced by stimulus material systematically influence error in time estimation. In particular, we hypothesized that the perceived duration of an event is affected by manipulations of the two emotional dimensions of affective valence and arousal. We used stimulus material previously standardized for affective valence and arousal in order to effectively manipulate these two affective dimensions.

\section{Factors That Affect Time Perception}

Several factors have been shown to affect perceived durations. Three variables are particularly relevant to the present study: (1) attention and amount of information processing, (2) arousal, and (3) affective valence.

Attention and amount of information processing. Attentional models of time perception have proposed that during a time judgment task, attentional resources allocated to the stimulus are subtracted from the attention that individuals devote to the processing of time. As a consequence, when an interesting stimulus or a stimulus that requires more attentional resources is presented during the interval to be estimated, fewer time units are processed and 
the individual tends to underestimate the temporal intervals (see, e.g., Thomas \& Weaver, 1975; Treisman, 1963; Zakay, 1992, 1993a, 1993b; Zakay \& Yehoshua, 1989).

In studies designed to verify the influence of attention on time perception, attentional variables have often been confused with arousal or emotional valence. For instance, Hawkins and Tedford (1976) had subjects listen to different prose passages recorded on tape. Subjects judged interesting tapes to be shorter in duration than noninteresting ones, in agreement with the predictions of attentional models of time perception. However, "interesting" tapes had a sexual content and therefore also involved higher levels of arousal as well as a positive valence.

Several measures of information processing of the stimulus have been studied in relation to time perception, such as interest, processing times, originality, complexity, and attention. It is always important to distinguish between the difficulty of a task and the complexity of a stimulus, because these factors refer to different cognitive sets. The former are related to active-productive processing, whereas the latter are related to passive-perceptual processing. The amount of cognitive processing during passive tasks cannot be directly measured (Zakay, 1993a; Wallace \& Rabin, 1960) since it depends on internal mental activity that does not require an overt response. A classic measure of the amount of attentional resources allocated to a stimulus (the primary stimulus) is the delay to react to a secondary probe stimulus (dual-task paradigm). This is an indirect but precise index, based on the assumption that the amount of attentional resources devoted to the secondary stimulus is inversely proportional to the amount devoted to the primary stimulus. However, performance in the primary task is affected by the presence of a secondary task. If the task of interest is the evaluation of a time interval, the introduction of an interfering task within the same period will create a strong confounding factor.

An alternative approach to examining attentional variables is to measure noninvasive indices of attention, such as heart rate, which does not require the introduction of an additional task.

Arousal and valence effects. Several studies have shown that activation (as operationally defined by the authors) can affect time evaluation. Activation levels have been manipulated in a number of ways, such as increase or decrease of body temperature (Fox, Bradbury, \& Hampton, 1967) and manipulation of circadian rhythms and administration of drugs (Gupta \& Cummings, 1986). Incrementing physical activation levels has been found to cause an overestimation of perceived time. However, Curton and Lordahl (1974) found that different activating methods (physical activity vs. threat of shock) have different effects on time perception. For methodological reasons, most methods used to induce activation cannot be qualitatively or quantitatively compared.

In several time estimation experiments, valence manipulation was performed in waiting conditions (Curton \& Lordahl, 1974; Edmonds, Cahoon, \& Bridges, 1981; Hare, 1963; Schiff \& Thayer, 1968). Block, George, and
Reed (1980) showed that waiting condition per se affects time judgments. Fraisse (1963) proposed that time estimates in waiting conditions might be independent of the valence of the stimulus and be associated uniquely to an enhanced attention to time. Therefore, it seems that these studies were more concerned with the expectancy condition than with valence manipulation. Indeed, during waiting it is not possible to control subjects' cognitive and emotional activity, since they are not engaged in any task.

Langer, Wapner, and Werner (1961) found shorter time estimates for subjects experiencing fear of danger than for subjects in a neutral condition. However, their study is seriously flawed by the fact that the pressure on the button that was used to estimate the period of time also caused the danger to disappear. Thayer and Schiff(1975) asked subjects to estimate the time interval spent in an eye-contact social task and manipulated the facial expression of the subject's partner, a critical factor that can influence the affective valence of an interpersonal contact. Time estimates were longer when combined with a negative-unpleasant (scowling-angry) than with a positive-pleasant (smiling-friendly) facial expression.

Watts and Sharrock (1984) showed that spider-phobic subjects gave longer estimates of a short interval spent observing a spider than did nonphobic controls. In this study as well, no attempt was made to control for arousal levels. Gupta and Cummings (1986) found that events that seem to occur quickly are perceived as more pleasant (positive) than those that seem to occur more slowly. In this study, time perception was the independent variable and was manipulated through changes in either physical activation (by changes in circadian rhythms and the use of caffeine) or the presentation of an external ticker.

In summary, the literature offers some evidence that negative conditions cause an overestimation of the time spent attending to them, and positive conditions cause an underestimation. However, studies manipulating more systematically emotional factors are still lacking.

\section{The Experiment}

In the present study, we investigated the effect of emotional stimuli on time perception, using psychophysiological measures as independent indices of attention and arousal. Several studies have shown that some psychophysiological variables reliably covary with rated emotional valence and arousal. For example, facial muscular activity is specifically related to differences in the pleasantness of the stimulus material, whereas skin conductance responses are strongly correlated with changes in rated arousal (Greenwald et al., 1989; Lang et al., 1993). Heart rate is a classic index of the amount of attention (also termed "orienting response") induced by brief perceptual stimuli such as photographic slides (Bradley, Cuthbert, \& Lang, 1990, 1991; Graham \& Clifton, 1966; Lacey \& Lacey, 1970).

The main purpose of the present experiment was to study the influence of stimulus-induced emotional arousal and affective valence on the estimation of temporal intervals spent passively attending to the stimulus itself (neither waiting for it nor acting on it). We used a set of standardized 
photographic slides rated for emotional valence and arousal to systematically manipulate these two dimensions. In order to measure the attentional processing and the arousal responses elicited during the viewing interval (i.e., during the time-processing period), heart rate (HR), as an index of attention and skin conductance responses (SCRs), as an index of arousal, were also collected.

The second goal of the experiment was to verify whether the method adopted to assess duration would modify the effect of valence and arousal on time perception. Two methods were used to judge durations, both within a prospective-judgment paradigm: estimation on an analog scale and reproduction of the interval by pushing a button. According to several authors (Clausen, 1950; Danziger \& Du Preez, 1963; Schiff \& Thayer, 1970), these two methods produce qualitatively different time evaluations. According to others (Zakay, 1993b), no difference can be found between them.

Finally, we investigated the effect of the duration of the interval to be estimated or reproduced. The emotional responses induced by the standardized slides develop within $6 \mathrm{sec}$ and then extinguish (Greenwald et al., 1989; Lang et al., 1993). Thus, we decided to choose three equally distanced intervals $(2,4$, and $6 \mathrm{sec})$ within this standardized 6-sec interval.

\section{METHOD}

\section{Subjects}

Fifty-three undergraduate students participated in the experiment as part of their class requirement. Subjects were randomly assigned to one of the two time-estimation conditions: evaluation on an ana$\log$ scale (27 subjects) or interval reproduction ( 26 subjects). Two subjects, 1 for each condition, failed to give some time judgments, and their remaining data were discarded from data analyses.

\section{Materials}

Eighteen colored slides were chosen from the International Affective Picture System (IAPS; Center for the Study of Emotion and Attention, 1995). These stimuli, used extensively in emotion research, have been standardized for self-assessed valence and arousal on very large samples of subjects across the world. In addition, other factors related to the attentional process induced by these slides have been investigated, including subjective interest ratings and slides' free-viewing times (Lang et al., 1993).

Five groups of slides that were homogeneous for valence, arousal, and content were selected according to IAPS standard ratings, as follows: (1) pleasant (range: $6.5-8.5$ ), high arousal (range: $6.5-7.5$ ) slides, representing erotic material; (2) pleasant (range: 6.5-8.5), low arousal (range: 4-5.7) slides, representing babies and animal puppies; (3) neutral (valence range: 4-5.5; arousal range: $2.5-3$ ) slides, representing household objects; (4) unpleasant (range: 1-4), low arousal (range: 4-5.7) slides, representing spiders and rats; (5) unpleasant (range: 1-4), high arousal (range: 6.5-7.5) slides, representing bloody human wounds. The 18 slides are described in the Appendix (Table A1).

In order to verify the arousal and valence ratings in our sample of subjects, ratings were collected during the . 'periment by means of the Self-Assessment-Manikin (SAM; Hoc 's, Cook \& Lang, 1985; Lang, 1980), two 9-point visual scales repı senting a cartoon subject ranging from sad to happy (emotional $v_{i}$ ence) and from calm to activated (arousal).

Each of the five groups included three slides, except for the neutral group, which included six. The four valence/arousal groups of slides were defined by the intersection between the valence dimension (two levels: low valence, negative emotion, and high valence, positive emotion) and the arousal dimension (two levels: low and high).

The neutral group was used only as a filler. The data for this group were discarded from statistical analysis since this condition was associated with an arousal level that is lower than all the other slides, and a valence halfway between pleasant and unpleasant slides. However, the mean values for these stimuli are reported in the tables as a nonemotional control condition.

The 18 slides were organized into three different sequences completely randomized over the whole sequence for slide category and independently randomized for duration intervals. The subjects were randomly assigned to one sequence upon their arrival in the laboratory. Within each emotional category, one slide (two for the neutral slides) was projected for $2 \mathrm{sec}$, one for 4 , and one for $6 \mathrm{sec}$. Each slide was projected equally frequently at the three intervals.

\section{Physiological Recordings}

Experimental events were controlled by a personal computer controlling a dedicated triggering device, Telema ${ }^{\mathrm{TM}}$ (designed for tachistoscopic experiments), with 1 -msec precision. Slide duration was controlled by an electronic shutter with a rise/fall time of less than $5 \mathrm{msec}$. Psychophysiological recording started $2 \mathrm{sec}$ before the stimulus onset and lasted for $10 \mathrm{sec}$. Data acquisition was performed by a Macintosh II computer and NB-MIO-16L-25 A/D board (National Instruments). Acquisition and data analysis programs were implemented in LabVIEW 3 (National Instruments) as described by Angrilli (1995). A Digitimer Ltd. (England) system amplified and filtered the physiological signals. HR was measured by using standard lead II electrode configuration. Electrocardiogram was sampled at $500 \mathrm{~Hz}$, passed through a software trigger, and converted into interbeat intervals before being stored. After the conversion, HR data were reduced off-line in half-second bins according to the harmonic mean criterion (Graham, 1978).

For (SCR), $\mathrm{Ag} / \mathrm{AgCl}$ electrodes (1 cm diameter, $\mathrm{K}-\mathrm{Y}$ jelly filling) were placed on the palmar side of the medial phalanges of the index and middle fingers of the nondominant hand. Electrodes were fed in a $0.5-\mathrm{V}$, constant-voltage transducer (Fowles et al., 1981), followed by an amplifier set to gain 5,000 and a high-pass filter set to a 5 -sec time constant: The signal was sampled at $20 \mathrm{~Hz}$. SCRs were scored as the maximum value (in micromhos) found within the 1st and 4th sec after slide onset (Prokasy \& Raskin, 1973). Log transformation $(\log [\mathrm{SCR}+1])$ normalized the distribution of the responses. HR and SCR data were computed as differences across a 2-sec baseline.

\section{Time Judgment}

Subjects were told at the beginning of the experimental session that their task would involve a time estimation. We adopted the prospective paradigm, which should be more likely to yield results in accordance with attentional theories. Within this paradigm, two different time estimation methods were used. Both judgments were made soon after the offset of each slide. In one case, the subject had to mark on a graduated analog scale $(0-10 \mathrm{sec}$ in $20-\mathrm{cm}$ length) the perceived duration of the stimulus. The ratings were measured as a distance on the scale rounded off to the nearest 10th of a second $(2 \mathrm{~mm})$. In the second case, the subject had to reproduce the interval by pushing a button for a duration that matched the duration of the perceived period. The reproduced interval was measured with $1-$ msec precision.

Both estimates of time duration were computed as a difference from the target period of time $(2,4$, or $6 \mathrm{sec})$ expressed as a proportion of the target period $\left(T_{\text {corrected }}=\left(T_{\text {estimated }}-T_{\text {target }}\right) / T_{\text {target }}\right.$ : Brown, 1985; Fanton, 1989; McConchie \& Rutschmann, 1970; Schiff \& Thayer, 1968, 1970; Treisman, 1963). In the range of short durations $(1-6 \mathrm{sec})$, time estimation is approximately in linear proportion to real time (Bobko, Thompson, \& Schiffman, 1977; Eisler, 
1975; Fraisse, 1984; Stevens, 1960). Therefore, this transformation was needed to compare different fixed-interval estimations (the scores are computed as percentage of error compared with the real interval) and to increase the homogeneity of the variances for statistical computations (the Greenhouse-Giessen epsilon values were higher after this transformation). We preferred this transformation rather than the equally viable and perhaps more traditional simple ratio, $T_{\text {estimated }} / T_{\text {target }}$ because it gives information about both the extent and direction of subjective estimations; negative values indicate absolute underestimation of the target period, whereas positive values indicate absolute overestimation. Statistical analyses were performed on the transformed data; the raw time estimations are shown, together with their standard deviations, in Tables A2 and A3.

\section{Procedure}

After giving informed consent, the subject was led into a dimly lit room and asked to sit in a reclining chair. The slide image had an area of $86 \times 58 \mathrm{~cm}$ and was projected at a distance of $170 \mathrm{~cm}$ from the subject's eyes $\left(29^{\circ} \times 19.5^{\circ}\right.$ of visual angle). After the electrodes were placed, the subject was familiarized with the SAM rating and the time estimation procedures. The subject was then given a booklet with a page for each slide. On every page, there were two SAM scales for arousal and valence ratings of the slide and, only for subjects from the analog estimation group, the analog scale for time estimation.

A push button was used to measure time reproduction. The subject was told to watch the slide the entire time it was projected on the screen. Soon after the picture offset, the subject had to mark on the analog time scale or to push the button reproducing the time interval. After time estimation, the subject was asked to rate the picture on both SAM dimensions (arousal and valence). To avoid an expectancy effect, a variable random interval $(25-40 \mathrm{sec})$ occurred between picture presentations: The subject was told to relax after the ratings.

In order to acquaint the subjects with the rating procedure, four slides were shown as practice with the rating procedures. After 5 min of relaxation, the experiment began with the projection of 18 slides ordered in one of three random sequences. At the end of the experiment, a debriefing questionnaire was administered to the subject in order to verify whether the instructions had been well understood during the experiment.

\section{Data Analysis}

Due to variations in stimulus duration across the conditions, special methodological considerations were required. The SAM procedure was standardized for a 6-sec presentation of stimulus material. Therefore, it was necessary to check for unusual responses in the 2- and 4-sec conditions.

Physiological responses were also analyzed. For methodological reasons, only responses achieved by the first $2-\mathrm{sec}$ epoch can be considered. Direct comparison of HR measured at 2, 4, and 6-sec intervals could not be performed because of the different number of data points in each duration condition. Therefore, statistical comparison of HR responses in the first $2 \mathrm{sec}$ after slide onset was per- formed. This epoch represents the first decelerative phase, which has been termed orienting (Bradley et al. 1990; Graham \& Clifton, 1966).

Given the latency of the SCR (about $2 \mathrm{sec}$ for the beginning of the response and $3-4 \mathrm{sec}$ for the maximum peak), it was analyzed between 1 and $4 \mathrm{sec}$ after stimulus onset (Prokasy \& Raskin, 1973). Thus, SCR is related only to the emotional activation elicited in the 1st sec. Since subsequent SCR peaks are affected by the activity after slide offset, analysis of the responses detected after $4 \mathrm{sec}$ was not performed. Therefore, it was expected that the main effects of the duration variable (2-, 4-, and 6-sec conditions) would show no differences among SCRs computed.

\section{RESULTS}

An analysis of variance (ANOVA) was computed for each dependent variable: transformed time estimates, SCRs, HR, and SAM arousal and valence ratings.

The design included four factors: one between subjects and three within subjects. The between-subjects factor was time estimation method (analog scale vs. interval reproduction). The three within-subjects factors were: (1) emotional valence (high valence/pleasant slides vs. low valence/unpleasant slides); (2) emotional arousal (high vs. low arousal), and (3) projection duration of the slides $(2,4$, and $6 \mathrm{sec})$.

\section{Time Estimate Analysis}

The main effect of time estimation method was highly significant $[F(1,49)=10.264, p<.002]$, indicating that mean $T_{\text {corr }}$ in the interval reproduction condition was significantly smaller than the analog scale ratings $(-0.364$ and -0.139 , respectively). Thus, the interval reproduction method led to a larger underestimation of the real durations than did the analog scale method (Tables 1 and 2). It is worth noting that the variance of analog scale ratings was three times larger than that for the interval reproduction ratings ( 0.136 and 0.046 , respectively). This larger variability for the estimation method is consistent with previous studies (Danziger \& Du Preez, 1963; Siegman, 1962). The main effects of valence, arousal, and duration did not reach statistical significance.

The method $x$ duration interaction was significant $[F(2,98)=4.607, p<.01]$, with post hoc analyses indicating that the largest difference between the two methods was observed at the 4-sec duration (Figure 1; Table 1).

The most important result, however, concerned valence and arousal effects. Although both the arousal

Table 1

Means and Standard Deviations of the Transformed Time Estimations for the Emotional and Neutral Slides-Interval Reproduction Method

\begin{tabular}{|c|c|c|c|c|c|c|c|c|c|c|}
\hline \multirow[b]{4}{*}{ Time } & \multicolumn{10}{|c|}{ Arousal } \\
\hline & \multicolumn{4}{|c|}{ Positive } & \multicolumn{4}{|c|}{ Negative } & & \\
\hline & \multicolumn{2}{|c|}{ Low } & \multicolumn{2}{|c|}{ High } & \multicolumn{2}{|c|}{ Low } & \multicolumn{2}{|c|}{ High } & \multicolumn{2}{|c|}{ Neutral } \\
\hline & $M$ & $S D$ & $M$ & $S D$ & $M$ & $S D$ & $M$ & $S D$ & $M$ & $S D$ \\
\hline $2 \mathrm{sec}$ & -.334 & .267 & -.363 & .241 & -.414 & .209 & -.198 & .285 & -.356 & .184 \\
\hline $4 \mathrm{sec}$ & -.340 & .180 & -.424 & .138 & -.400 & .189 & .391 & .180 & -.370 & .182 \\
\hline $6 \mathrm{sec}$ & -.332 & .212 & -.421 & .182 & -.397 & .180 & -.354 & .226 & -.365 & .198 \\
\hline
\end{tabular}




\begin{tabular}{|c|c|c|c|c|c|c|c|c|c|c|}
\hline \multirow[b]{5}{*}{ Time } & \multicolumn{10}{|c|}{$\begin{array}{l}\text { Table } 2 \\
\begin{array}{l}\text { Means and Standard Deviations of the Transformed Time Estimations } \\
\text { for the Emotional and Neutral Slides-Analog Scale Method }\end{array}\end{array}$} \\
\hline & \multicolumn{10}{|c|}{ Arousal } \\
\hline & \multicolumn{4}{|c|}{ Positive } & \multicolumn{4}{|c|}{ Negative } & \multirow{2}{*}{\multicolumn{2}{|c|}{ Neutral }} \\
\hline & \multicolumn{2}{|c|}{ Low } & \multicolumn{2}{|c|}{ High } & \multicolumn{2}{|c|}{ Low } & \multicolumn{2}{|c|}{ High } & & \\
\hline & $M$ & $S D$ & $M$ & $S D$ & $M$ & $S D$ & $M$ & $S D$ & $M$ & $S D$ \\
\hline $2 \mathrm{sec}$ & -.124 & .483 & -.155 & .452 & -.256 & .387 & -.151 & .433 & -.206 & .367 \\
\hline $4 \mathrm{sec}$ & -.068 & .328 & -.140 & .345 & -.121 & .353 & -.052 & .402 & -.132 & .337 \\
\hline $6 \mathrm{sec}$ & -.136 & .383 & -.161 & .330 & -.134 & .382 & -.174 & .311 & -.181 & .305 \\
\hline
\end{tabular}

$[F(1,49)=0.153]$ and valence $[F(1,49)=0.077]$ main effects failed to reach significance, the interaction of valence $\times$ arousal was highly significant $[F(1,49)=$ $15.151, p<.0003$; Figure 2]. Positive and negative valence conditions showed an opposite trend at low- and high-arousal levels. In the high-arousal condition, positive slides were underestimated more than negative slides ( $T_{\text {corr }}$ were -0.277 and -0.220 , respectively, for positive and negative slides), whereas in the low-arousal condition, positive slides were underestimated less than negative slides $(-0.222$ and -0.287 , respectively). Post hoc simple effects analysis showed significant differences between all levels $[F(1,49)>4.532, p<.04]$. That is, we found significant differences between positive and negative slides at both levels of arousal, as well as between low and high arousal at both levels of valence. Neutral slides $(M=-0.268)$, which were used as fillers, showed time-estimation values in between those of emotional stimuli, somewhat more underestimated than the mean value of all the emotional conditions $(M=-0.251)$.

The three-way interaction method $\times$ valence $X$ arousal failed to reach significance $[F(1,49)=1.221]$, indicating that the same trend appeared in both estimation methods. The arousal $\times$ duration interaction (Figure 3 ) was significant $[F(2,49)=3.635, p<.03]$. In the low-arousal condition, underestimation decreased from the $2-\sec \mathrm{du}-$

Time estimation: Method and Duration

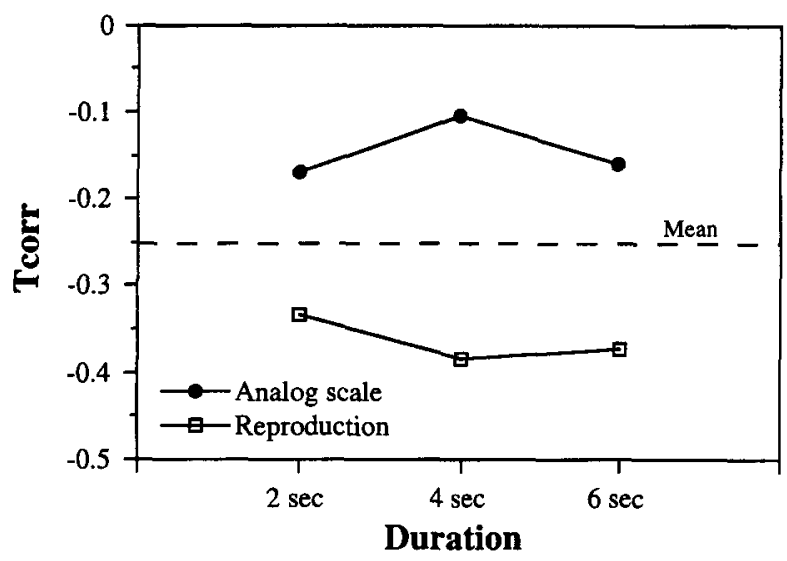

Figure 1. Method $\times$ duration. Mean values of the analog scale and reproduction interval modalities computed for $2-$, 4-, and 6-sec duration intervals. In ordinate duration estimations are expressed as percentage of variation: $T_{\text {corr }}=\left(T_{\text {estimated }}-T_{\text {target }}\right) / T_{\text {target }}$. ration $(-0.282)$ to the 6 -sec duration $(-0.250)$, whereas in the high-arousal condition, underestimation increased in the same interval $(-0.217$ and -0.278 , respectively, for 2 and $6 \mathrm{sec}$ ). Post hoc simple effects analysis showed a significant difference of arousal in the 2 -sec condition $[F(2,49)=4.168, p<0.05]$.

\section{SCRs Analysis}

SCRs showed two significant main effects. There was a highly significant effect of method; during interval reproduction. all the values were higher than those of the analog scale condition [0.27 vs. 0.11 micromhos; $F(1,51)=17.568, p<.0001]$. Also highly significant was the effect of arousal $[F(1,51)=32.903, p<.0001]$. Skin conductance was higher for high-arousal slides ( 0.22 micromhos) than for low-arousal slides $(0.16$ micromhos) in both estimation methods (Table 3 ).

The method $\times$ arousal interaction failed to reach significance $[F(1,51)=2.562]$. As predicted, the duration effect also failed to reach significance $[F(2,51)=0.295]$. This indicates that the SCR effectively represented the emotional responses restricted to the first $2 \mathrm{sec}$ of each slide and that any differences associated with the offset of the shortest slides were avoided by the analysis method used.

\section{HR Analysis}

HR was analyzed in a time window that included the first $2 \mathrm{sec}$ after slide onset (interval during which all slides were observed regardless of the different durations of projection-2, 4, or $6 \mathrm{sec}$ ). Results showed a significant effect of valence $[F(1,51)=4.962, p<.03]$ : Positive slides elicited an increase in HR responses $(0.320$ beats per min, $S D=2.46$ ), whereas negative slides induced a deceleration $(-0.750$ beats per $\min , S D=2.63$; Table 4$)$.

Both the effects of duration $[F(2,51)=2.390]$ and the duration $\times$ valence interaction $[F(2,51)=0.210]$ failed to reach significance. As with SCR, this means that the different durations of slide projection did not affect the psychophysiological response induced in the first $2 \mathrm{sec}$.

\section{SAM Ratings Analysis}

The SAM valence ratings confirmed the expected highly significant effect of valence $[F(1,49)=1058.528$, $p<.0001]$, with positive slides producing higher ratings than negative slides. SAM arousal ratings also showed a significant difference between low- and high-arousal 


\section{Time estimation: Arousal and Valence}

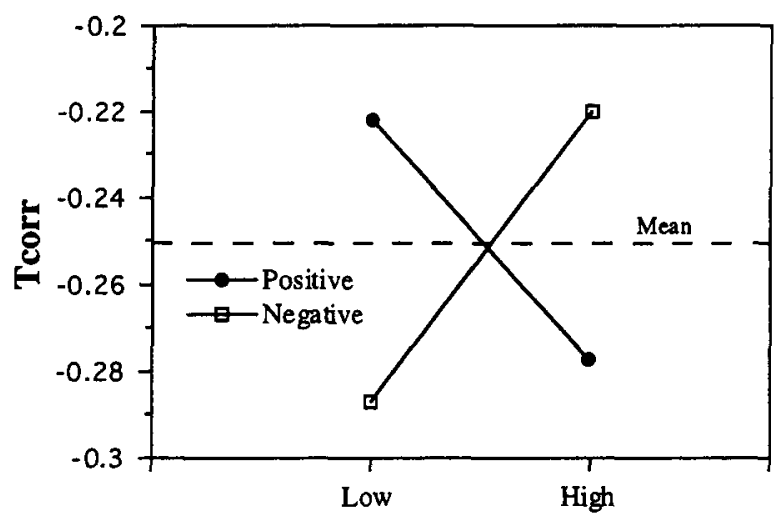

Arousal

Figure 2. Valence $\times$ arousal. Slides were selected along valence (pleasant vs. unpleasant) and arousal (high vs. low) dimensions according to the standardized (a priori) Self-Assessment Manikin ratings. In ordinate duration estimations are expressed as percentage of variation: $T_{\text {corr }}=\left(T_{\text {estimated }}-T_{\text {target }}\right) / T_{\text {target }}$.

slides $[F(1,49)=138.891, p<.0001]$. Since neither the main effect of duration nor its interactions with other factors reached significance, we can conclude that different slide projection intervals did not produce any difference in perceived valence and arousal as assessed by SAM ratings.

\section{DISCUSSION}

\section{Physiological Results}

Higher SCR values were measured for the reproduction method group than for the analog scale method group. According to the literature, SCR is rated as an index of pure sympathetic activity and arousal (Greenwald et al., 1989; Lang et al., 1993). The observed effect can easily be interpreted as a response to the higher arousal induced by preparation for the motor performance (i.e., pushing a button). More importantly, the data showed a clear-cut difference in SCR between lowand high-arousal conditions, for both method groups (Table 3). Specifically, high-arousal slides elicited higher sympathetic activity than did low-arousal slides within the first $2 \mathrm{sec}$ of slide viewing (Greenwald et al., 1989; Lang et al., 1993). This finding suggests that discrimination for both dimensions was completed after the first $2 \mathrm{sec}$ of presentation. This conclusion is supported by SAM data on both valence and arousal reported by the subjects, which showed a remarkable stability across durations.

HR data demonstrated differences across valence levels. There was an HR increase for positive slides (high valence) and an HR decrease for negative slides (low valence). HR deceleration to unpleasant stimuli is well documented in the literature (Bradley et al., 1990, 1991; Hare, Wood, Britain, \& Shadman, 1970; Lang et al., 1990, 1993; Winton, Putnam, \& Krauss, 1984). In general, a deceleration to brief stimuli is interpreted as an orienting reaction (Bradley et al. 1990, 1991; Graham \&
Clifton, 1966; Lacey \& Lacey, 1970, named it "stimulus intake"). Therefore, the decrease in HR for unpleasant stimuli in the present experiment could be interpreted as an attentional effect: Unpleasant slides would induce a larger orienting reaction than pleasant slides. This is consistent with another indirect measure of attention recently used on the same kind of stimulus material by Cuthbert, Bradley, and Lang (1996). In a study that included a comparison of free-viewing times in a sample of IAPS slides, subjects watched negative slides longer than positive slides at every level of arousal. The authors concluded that, keeping arousal constant, the negative slides were always more interesting than the positive ones. Both SAM self-reports and physiological recordings showed that the arousal and valence discrimination was completed within the first 2 sec.

\section{Time Estimation Results}

Difference between evaluation and reproduction methods. In all conditions tested, time was underestimated. This effect can be interpreted as a function of the overall attentional set, which is determined by the perceptual slide-viewing task (Lang et al., 1993) together with the time-prospective estimation task. In prospective paradigms of time estimation, a general underestimation of the experienced intervals is expected (Thomas \& Weaver, 1975; Treisman, 1963; Zakay, 1992, 1993a, 1993b; Zakay \&Yehoshua, 1989).

Furthermore, durations were more underestimated in the reproduction condition. Like the present study, the study of Osato, Ogawa, and Takaoka (1995) showed a clearer underestimation for the reproduction method than for the verbal estimation method. In general, larger underestimations have been found to be associated with tasks with increasing complexity in prospective experimental designs (Sawyer, Meyers, \& Huser, 1994). Thus, our reproduction method, using button-press request, probably enhanced attention to time and increased the demand and complexity of the slide-viewing task.

\section{Time estimation: Arousal and Duration}

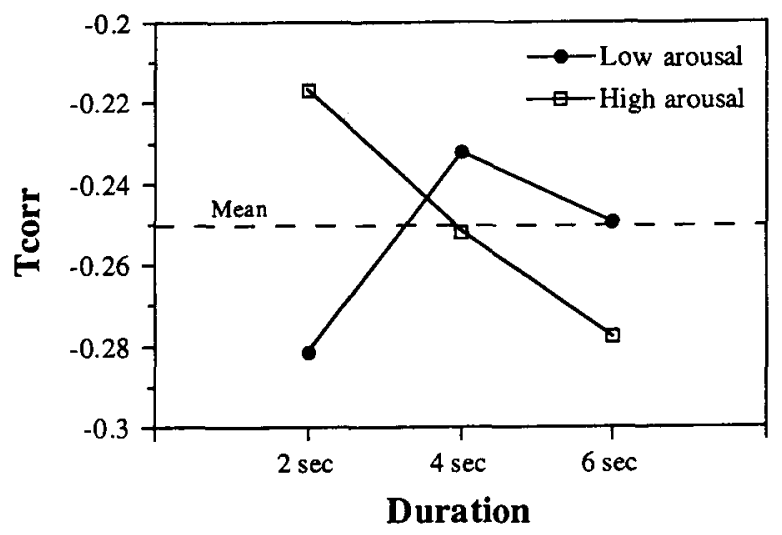

Figure 3. Duration $\times$ arousal. Low- and high-arousal slides were selected according to the standardized (a priori) Self-Assessment Manikin ratings. In ordinate duration estimations are expressed as percentage of variation: $T_{\text {corr }}=\left(T_{\text {estimated }}-T_{\text {target }}\right) / T_{\text {target }}$. 
Table 3

\begin{tabular}{|c|c|c|c|c|c|c|c|c|c|c|}
\hline \multirow[b]{5}{*}{ Time } & Me & nd S & $\begin{array}{l}\text { ard I } \\
\text { Emo }\end{array}$ & $\begin{array}{l}\text { tion } \\
\text { al an }\end{array}$ & $\begin{array}{l}\text { e Sl } \\
\text { utral }\end{array}$ & $\begin{array}{l}\text { ondu } \\
\text { es at }\end{array}$ & $\begin{array}{l}\text { ce } R \\
\text { and }\end{array}$ & nses & & \\
\hline & \multicolumn{10}{|c|}{ Arousal } \\
\hline & \multicolumn{4}{|c|}{ Positive } & \multicolumn{4}{|c|}{ Negative } & & \\
\hline & \multicolumn{2}{|c|}{ Low } & \multicolumn{2}{|c|}{ High } & \multicolumn{2}{|c|}{ Low } & \multicolumn{2}{|c|}{ High } & \multicolumn{2}{|c|}{ Neutral } \\
\hline & $M$ & $S D$ & $M$ & $S D$ & $M$ & $S D$ & $M$ & $S D$ & $M$ & $S D$ \\
\hline $2 \mathrm{sec}$ & .14 & .28 & .23 & .23 & .18 & .22 & .24 & .23 & .13 & .20 \\
\hline $4 \mathrm{sec}$ & .16 & .19 & .21 & .23 & .13 & .17 & .24 & .20 & .13 & .18 \\
\hline $6 \mathrm{sec}$ & .17 & .20 & .20 & .22 & .18 & .23 & .19 & .19 & .12 & .14 \\
\hline
\end{tabular}

Note-Units were measured in micromhos and log transformed in order to normalize the distribution of the responses.

The literature on time perception reports differences between evaluation and reproduction methods (Clausen, 1950), but also larger variability and less reliability in evaluation methods than in reproduction (Danziger \& Du Preez, 1963; Schiff \& Thayer, 1970). However, a recent study did not find any significant difference between verbal estimates and reproduction methods (Zakay, 1993b). In the present experiment, the analog scale method led to more accurate absolute duration judgments than did the interval reproduction method, but it led also to a larger variance. Clausen has suggested that analog scale estimation requires a cognitive "translation function" between perception and the acquired standardized units of measure for time. This translation function would be different across individuals, and this interindividual variability could explain the larger variances found with this method.

The significant interaction found between method and duration also provides some interesting hints regarding the differences in time-estimation methods. The 4-sec duration was overestimated in the analog scale condition compared with the 2-sec and 6-sec durations, whereas it was underestimated in the interval reproduction condition compared with the 2-sec duration (Figure 1). This difference between the two methods suggests that $4 \mathrm{sec}$ is the temporal transition between two different strategies in time evaluation, one for shorter durations (under 3-4 sec) and the other for longer durations. This interpretation is supported by Elbert, Ulrich, Rockstroh, \& Lutzenberger's (1991) research, in which subjects were required to reproduce different temporal intervals in the range of 1-8 sec. They found a larger cortical negativity (contingent negative variation) for intervals shorter than 3-4 sec than for longer ones. The authors suggested that reproduction of longer time intervals is a more complex process than reproduction of short intervals, because it might require elaborate and specific cognitive processes such as memory, decision and comparison, and individuation of interval cues.

Valence and arousal effects. In this section, we refer to under- and overestimations only as measures relative to the overall mean of the four experimental conditions. The most relevant finding of the present experiment was the difference found between the low-arousal condition and the high-arousal condition. At low levels of arousal, the duration of negative slides was underestimated, and the duration of positive slides was overestimated. At high levels of arousal, however, positive slide duration was underestimated relative to the duration of negative slides. As seen in the HR results, negative slides, regardless of the arousal level, elicited a stronger orienting reaction from the subjects. This result suggests that more attention was paid to negative slides than to positive slides. Consequently, according to attentional models, the duration of negative slides should be underestimated. However, negative-low arousal and positive-high arousal slides (i.e., the stimuli inducing less attentional responses) were underestimated. This is in contrast to negative-high-arousal slides (with larger attentional responses), and positive-low-arousal slides (with a lower attentional response), which were overestimated. These results suggest the existence of two different patterns of time estimation, one activated in low-arousal situations and the other in high-arousal situations that show an opposite behavior at positive and negative valence levels.

It is likely that time perception during presentation of low-arousal material is affected by attentional factors. The low-arousal trend is fully consistent with the pre-

Table 4

Means and Standard Deviations of the Heart Rate Change for the Emotional and Neutral Slides at 2, 4, and 6 Sec

\begin{tabular}{|c|c|c|c|c|c|c|c|c|c|c|}
\hline \multirow[b]{4}{*}{ Time } & \multicolumn{10}{|c|}{ Arousal } \\
\hline & \multicolumn{4}{|c|}{ Positive } & \multicolumn{4}{|c|}{ Negative } & & \\
\hline & \multicolumn{2}{|c|}{ Low } & \multicolumn{2}{|c|}{ High } & \multicolumn{2}{|c|}{ Low } & \multicolumn{2}{|c|}{ High } & \multicolumn{2}{|c|}{ Neutral } \\
\hline & $M$ & $S D$ & $M$ & $S D$ & $M$ & $S D$ & $M$ & $S D$ & $M$ & $S D$ \\
\hline $2 \mathrm{sec}$ & 1.05 & 5.18 & -.88 & 5.71 & -2.20 & 4.93 & -.38 & 5.33 & -.62 & 4.21 \\
\hline $4 \mathrm{sec}$ & .67 & 4.73 & -.41 & 6.71 & -.71 & 5.91 & -1.34 & 5.58 & .34 & 3.32 \\
\hline $6 \mathrm{sec}$ & .48 & 6.29 & 1.01 & 5.24 & .39 & 6.11 & -.27 & 5.52 & -.13 & 3.87 \\
\hline
\end{tabular}


dictions of attentional theories of time perception. These models predict that the duration of an interesting (or more complex) stimulus should be underestimated, because the information processing of the stimulus requires a larger amount of attentional resources. Thus, positive lowarousal slides, inducing less information processing, are relatively overestimated, whereas negative low-arousal slides, inducing a larger amount of information processing, are relatively underestimated. Attentional theories, however, cannot account for the high-arousal results, in which negative slide durations (showing attentional responses) were overestimated compared with positive ones (with weaker attentional responses).

Some studies are consistent with the high-arousal trend found in the present experiment. Thayer and Schiff (1975) found that negative facial expressions yielded overestimation of temporal durations. Negative social contacts are clear ecological situations that provoke avoidance reactions, and thus, probably, high emotional arousal. Watts and Sharrock (1984) found that phobic patients overestimated small intervals of time during phobic exposure. Phobic objects are perceived by patients in such an aversive way that they elicit a strong avoidance response and a clear physiological defense response (Fredrikson, 1981; Marks, 1969). Phobic objects can be considered as aversive-high-arousal stimuli.

The high-arousal trend seems to conflict with the attentional models. Negative slides evoked an avoidance reaction. Since subjects were prevented from producing avoidance behavior, the projection times for negative slices were perceived as too long (overestimated). Positive slides, on the contrary, evoked an approaching reaction and were perceived as not long enough (underestimated).

This explanation of arousal and valence effects implies the existence of a double mechanism triggered by arousal levels: an attention-driven mechanism at lowarousal levels, clearly consistent with attentional models, and an emotion-driven mechanism at high-arousal levels. Similar double mechanisms have already been described in the psychophysiological literature. Sokolov (1963) first described a shift from an orienting to a defense response when a tone of increasing intensity was presented. Recent studies used the startle reflex paradigm to examine both attentional and valence motivational mechanisms during presentation of emotional slides (Bradley, Cuthbert, \& Lang, 1993).

Consistent with our results, Cuthbert et al. (1996) showed that low-arousal negative slides elicited a smaller startle response (indicating a larger attentional activity because startle reflex is proportionally inhibited by attentional engagement) than did positive slides. With increasing arousal, startle responses showed a different trend, interpreted as emotion driven, with larger aversive responses to negative slides and smaller appetitive responses to positive slides. This last valence-dependent effect has been observed previously in a number of studies (Bradley et al., 1990, 1991, 1993). The authors concluded that the arousal level caused a shift between the two different motivational sets, one attentional and the other affective. In accordance with this interpretation, time perception seems to be a sensitive index of the direction of the action tendency. An approach-interesting direction, indicated by a relative time underestimation, and a withdrawal-boring direction, indicated by a relative time overestimation, would be induced by a mechanism driven by the informational content of the stimulus. An approach-appetitive direction, indicated by time underestimation, and a withdrawal-aversive direction, indicated by time overestimation, would be regulated by a mechanism driven by the affective valence of the stimulus.

It appears relevant that the interaction between valence and arousal was reliably seen at all duration levels $(2,4$, and $6 \mathrm{sec}$ ) and for both methods. These results suggest that arousal and valence effects on time estimation were quite capable of overwhelming the cognitive processes and response conditions involved in time estimation.

A parallel general mechanism can be hypothesized for explaining the arousal $\times$ duration interaction. In the first $2 \mathrm{sec}$, the duration of high-arousal slides was overestimated, regardless of the valence. According to the double mechanism previously proposed, it is likely that the early effect of high-arousal overestimation observed at 2 sec was mostly emotional, whereas the subsequent underestimation at $6 \mathrm{sec}$ was mostly attentional. On the other hand, low-arousal stimuli probably elicited only an attentional set, with an early (2-sec) approach-interesting underestimation decreasing with time (due to the withdraw-boring effect). Thus, for stimuli of long duration, the attentional set tends to prevail, whereas the emotional set would be given priority in the early phase of processing.

Recent psychophysiological and neurobiological studies support this hypothesis. There is evidence that emotionally arousing stimuli are processed very quickly in the central nervous system. Öhman and Soares (1994) found unconscious preattentional responses to phobic masked stimuli lasting only $30 \mathrm{msec}$ in subjects who reported no awareness of the content and characteristics of the stimuli. It has been proposed that two different neural pathways, one subcortical and one cortical, are responsible for emotional stimulus processing (LeDoux, 1995). The subcortical pathway is quickly activated by the biologically relevant - highly activating and potentially dangerous-stimuli but receives only incomplete information. The cortical pathway is slower, but processes more precise information regarding the nature of the stimuli and is able to inhibit possible early erroneous responses elicited by the first pathway. The subcortical system can rapidly activate response programs (physiological autonomic responses) for avoidance and fear-related behaviors. LeDoux's findings are consistent with the early high-arousal effect that we have observed. For the purpose of survival, the early avoidance response (mediated by the subcortical way described above) is expected to be dominant over the appetitive response. Indeed, the relative overestimation induced by the high- 
arousal stimuli at the shortest interval $(2 \mathrm{sec})$ progressively shifted to underestimation at 4 and $6 \mathrm{sec}$, whereas lowarousal stimuli became progressively less underestimated.

The psychophysiological and neurophysiological evidence for a double mechanism is also in line with a biologically adaptive function. The approach-withdrawal attentional mechanism would be aimed at optimizing the gathering of relevant information from the environment and avoiding loss of time during low-information conditions. The appetitive-aversive emotional mechanism would prepare the organism to react promptly in the right direction to the pleasant-unpleasant stimuli. Obviously, many other factors would affect the arousal-shifting threshold, such as the internal state of the organism, the context in which the stimulation appears, and prior experience.

In summary, our results show evidence of an effect on time estimation due to the manipulation of two primary components of emotions, affective valence and level of arousal. The interaction between these two factors is in line with the coexistence of two different mechanisms for the evaluation of perceived time. The first mechanism is faster, is emotion driven, and is triggered in high-arousal situations. The second mechanism is slower, attention driven, and works in low-arousal situations. Although the low-arousal mechanism is fully accounted for by the attentional models of time perception, the results can be interpreted more consistently by means of the psychobiological model. In light of these models, time perception seems strongly related to the action tendency.

\section{REFERENCES}

ANGRILLI, A. (1995). PSAAL: A LabVIEW 3 program for data acquisition and analysis in psychophysiological experiments. Behavior, Research Methods, Instruments, \& Computers, 27, 367-374.

ARGYLE, M. (1975). Bodily communication. London: Methuen.

Block, R. A., George, E. J., \& Reed, M. A. (1980). A watched pot sometimes boils: A study of duration experience. Acta Psychologica, 46, 81-94.

Boвko, D. J., Thompson, J. G., \& Schiffman, H. R. (1977). The perception of brief temporal intervals: Power functions for auditory and visual stimulus interval. Perception, 6, 703-709.

Bradley, M. M., CuthberT, B. N., \& LANG, P. J. (1990). Startle reflex modification: Emotion or attention? Psychophysiology, 27, 513-522.

Bradley, M. M., Cuthbert, B. N., \& LaNG, P. J. (1991). Startle and emotion: Lateral acoustic probes and the bilateral blink. Psychophysiology, 28, 285-295.

Bradley, M. M., Cuthbert, B. N., \& Lang, P. J. (1993). Pictures as prepulse: Attention and emotion in startle modification. Psychophysiology, 30, 541-545.

Brown, S. W. (1985). Time perception and attention: The effect of prospective versus retrospective paradigms and task demands on perceived duration. Perception \& Psychophysics, 38, 115-124.

Center for the Study of Emotion and AtTEntion (1995). The international affective picture system [Photographic slides]. Gainesville, FL: Author.

Chance, R. B. (1980). An ethological assessment of emotions. In R. Plutchik \& H. Kellerman (Eds.), Emotion, 1: Theories of emotions (pp. 121-134). New York: Academic Press.

Clausen, J. (1950). An evaluation of experimental methods of time judgment. Journal of Experimental Psychology, 40, 756-761.

Curton, E. D., \& LordaHL, D. S. (1974). Effects of attentional focus and arousal on time estimation. Journal of Experimental Psychology, 103, 861-867.

Cuthbert, B. N., Bradley, M. M., \& Lang, P. J. (1996). Probing picture perception: Activation and emotion. Psychophysiology, 33, 103-111.

DAMASIO, A. R. (1994). Descartes' ermor: Emotion, reason and the human brain. New York: Grosset/Putnam.

Danziger, K., \& Du Preez, P. D. (1963). Reliability of time estimation by the method of reproduction. Perceptual \& Motor Skills, 16, 879-884.

Edmonds, E. M., CaHoon, D., \& Bridges, B. (1981). The estimation of time as a function of positive, neutral, or negative expectancies. Bulletin of the Psychonomic Society, 17, 259-260.

EISLER, H. (1975). Subjective duration and psychophysics. Psychological Review, 82, 429-450.

Elbert, T., Ulrich, R., Rockstroh, B., \& LutZenberger, W. (1991). The processing of temporal intervals reflected by CNV-like brain potentials. Psychophysiology, 28, 648-655.

FANTON, V. (1989). Does the psychophysical method affect the time error? Bulletin of the Psychonomic Society, 27, 559-562.

Fowles, D. C., Christie, M. J., Edelberg, R., Grings, W. W., LykKen, D. T., \& Venables, P. H. (1981). Committee report. Publication recommendations for electrodermal measurements. Psychophysiology, 18, 232-239.

Fox, R. H., Bradbury, P. A., \& HAMPton, I. F. (1967). Time judgment and body temperature. Journal of Experimental Psychology, 75, 88-96.

Fraisse, P. (1963). The psychology of time. New York: Harper \& Row.

FRAISSE, P. (1984). Perception and estimation of time. Annual Review of Psychology, 35, 1-36.

FredRIKSON, M. (1981). Orienting and defensive reactions to phobic and conditioned fear stimuli in phobics and normals. Psychophysiology, 18, 456-465.

Graham, F. K. (1978). Constraints on measuring heart rate and period sequentially through real and cardiac time. Psychophysiology, 15, 492-495.

Graham F. K., \& Clifton, R. K. (1966). Heart rate change as a component of the orienting response. Psychological Bulletin, 65, 305-320.

Greenwald, M. K., CoOK, E. W., \& LANG, P. J. (1989). Affective judgment and psychophysiological response: Dimensional covariation in the evaluation of pictorial stimuli. Journal of Psychophysiology, 3, 51-64.

Gupta, S., \& Cummings, L. L. (1986). Perceived speed of time and task affect. Perceptual \& Motor Skills, 63, 971-980.

HARE, R. D. (1963). The estimation of short intervals terminated by shock. Journal of Clinical Psychology, 19, 378-380.

Hare, R. D., Wood, K., Britain, S., \& Shadman, J. (1970). Autonomic responses to affective visual stimuli. Psychophysiology, 7, 408-417.

HAWkins, M. F., \& TEDFORD, W. H., JR. (1976). Effects of interest and relatedness on estimated duration of verbal material. Bulletin of the Psychonomic Society, 8, 301-302.

HoDES, R. L., COOK, E. K., \& LANG, P. J. (1985). Individual differences in autonomic response: Conditioned association or conditioned fear? Psychophysiology, 22, 545-560.

LACEY, J. I., \& LACEY, B. C. (1970). Some autonomic-central nervous system interrelationships. In P. Black (Ed.), Physiological correlates of human emotion (pp. 205-227). New York: Academic Press.

LANG, P. J. (1980). Behavioral treatment and bio-informational assessment: Computer applications. In J. B. Sidowski, J. H. Johnson, \& T. A. Williams (Eds.), Technology in mental health care delivery systems (pp. 119-137). Norwood, NJ: Ablex.

LANG, P. J. (1984). Cognition in emotion: Concept and action. In C. E. Izard, J. Kagan, \& R. B. Zajonc (Eds.), Emotions, cognitions, and behavior (pp. 192-228). Cambridge: Cambridge University Press.

Lang, P. J., Bradley, M. M., \& Cuthbert, B. N. (1990). Emotion, attention, and the startle reflex. Psychological Review, 97, 377-398.

lang, P. J., Greenwald, M. K., Bradley, M. M., \& Hamm, A. O. (1993). Looking at pictures: Affective, facial, visceral, and behavioral reactions. Psychophysiology, 30, 261-273.

LANGER, J., WAPNER, S., \& WERNER, H. (1961). The effect of danger upon the experience of time. American Journal of Psychology, 74, 94-97.

LEDoux, J. E. (1995). Emotion: Clues from the brain. Annual Review of Psychology, 46, 209-235. 
MARKs, I. M. (1969). Fears and phobias. London: Heinemann.

McConchiE, R. D., \& RutschmanN, J. (1970). Reliability of time estimation: Effect of a preceding reproduction series on the reliability of subsequent verbal estimates of the same standard stimuli. Perceptual \& Motor Skills, 31, 51-55.

Öhman, A., \& Soares, J. J. F. (1994). "Unconscious anxiety": Phobic responses to masked stimuli. Journal of Abnormal Psychology, 103, 231-240.

Osato, E., OGaWA, N., \& TAKaOKA, N. (1995). Relations among heart rate, immediate memory, and time estimation under two different instructions. Perceptual \& Motor Skills, 80, 831-842.

PLuTchiK, R. (1962). The emotions: Facts, theories and a new model. New York: Random House.

Prokasy, W., \& RASKIN, D. (1973). Electrodermal activity in psychological research. New York: Academic Press.

SAWYER, T. F., Meyers, P. J., \& Huser, S. J. (1994). Contrasting task demands alter the perceived duration of brief time intervals. Perception \& Psychophysics, 56, 649-657.

SCHIFF, W., \& ThAYER, S. (1968). Cognitive and affective factors in temporal experience: Anticipated or experienced pleasant and unpleasant sensory events. Perceptual \& Motor Skills, 26, 799-808.

SCHIFF, W., \& THAYER, S. (1970). Cognitive and affective factors in temporal experience: Judgments of intrinsically and extrinsically motivated successful and unsuccessful performances. Perceptual \& Motor Skills, 30, 895-902.

SchumanN, J. (1990). The role of the amygdala as a mediator of affect and cognition in second language acquisition. In P. Alatis (Ed.), Proceedings of the Georgetown University Round Table on Language and Linguistics (pp. 169-176). Washington, DC: Georgetown University Press.

SchumanN, J. (1994). Where is cognition? Emotion and cognition in second language acquisition. Studies in Second Language Acquisition, 16, 231-242.

SiEGMAN, A. W. (1962). Intercorrelation of some measures of time estimation. Perceptual \& Motor Skills, 14, 381-382.

SoKolov, Y. N. (1963). Perception and the conditioned reflex. (S. W. Waydenfeld, Trans.). New York: Macmillan. (Original work published 1958)

Stevens, S. (1960). The psychophysics of sensory function. American Scientist, 48, 226-253.

TELlegen, A. (1985). Structures of mood and personality and their relevance to assessing anxiety, with an emphasis on self-report. In A. H. Tuma \& J. D. Maser (Eds.), Anxiety and the anxiety disorders (pp. 681-706). Hillsdale, NJ: Erlbaum.

ThAYER, S., \& SCHIFF, W. (1975). Eye-contact, facial expression, and the experience of time. Journal of Social Psychology, 95, 117-124.

Thomas, E. A. C., \& Weaver, W. B. (1975) Cognitive processing and time perception. Perception \& Psychophysics, 17, 363-367.

Treisman, M. (1963). Temporal discrimination and the indifference interval: Implications for a model of the "internal clock." Psychological Monographs, 77 (13)

Wallace, M., \& Rabin, A. (1960). Temporal experience. Psychological Bulletin, 57, 213-233.

WATtS, F. N., \& SharRoCK, R. (1984). Fear and time estimation. Perceptual \& Motor Skills, 59, 597-598.
Winton, W. M., Putnam, L. E., \& Krauss, R. M. (1984). Facial and autonomic manifestations of the dimensional structure of emotion. Journal of Experimental Social Psychology, 20, 195-216.

ZAKAY, D. (1992). The role of attention in children's time perception. Journal of Experimental Child Psychology, 54, 355-371.

ZAKAY, D. (1993a). Relative and absolute duration judgments under prospective and retrospective paradigms. Perception \& Psychophysics, 54, 656-664.

ZAKAY, D. (1993b). Time estimation methods-Do they influence prospective duration estimates? Perception, 22, 91-101.

ZAKAY, D., \& YeHoshuA, T. (1989). Awareness of attention allocation and time estimation accuracy. Bulletin of the Psychonomic Society, 27, 209-210

\section{NOTE}

1. The term arousal originated from neurophysiology's ARAS (ascending reticular activating system), a subcortical structure able to induce widespread and unspecific activation-alertness of the whole brain. In particular, the term arousal in psychophysiology refers to the phasic component of the central and sympathetic nervous system activation induced by a brief stimulation such as a tone or a slide. Skin conductance is the index showing the largest correlation with arousal, considered both as sympathetic activation and as self-reported arousal.

\section{APPENDIX}

Table A1

List of Slides (by IAPS Slide Number)

Pleasant low-arousal slides:

171 dog pets

205 happy baby

175 rabbits

Pleasant high-arousal slides:

469 naked couple

468 erotic couple

466 kissing couple (faces)

Neutral slides:

709 book

715 umbrella

705 hair dryer

708 fork

700 rolling pin

706 empty trash can

Unpleasant low-arousal slides:

120 big spider on banana

128 rat in the dirt

914 dead cow

Unpleasant high-arousal slides:

317 baby with eye tumor

300 smashed face

312 dead cut body

Table A2

Means (in Seconds) and Standard Deviations of the Untransformed Time Estimations for the Emotional and Neutral Slides-Analog Scale Method

\begin{tabular}{|c|c|c|c|c|c|c|c|c|c|c|}
\hline \multirow[b]{4}{*}{ Time } & \multicolumn{10}{|c|}{ Arousal } \\
\hline & \multicolumn{4}{|c|}{ Positive } & \multicolumn{4}{|c|}{ Negative } & & \\
\hline & \multicolumn{2}{|c|}{ Low } & \multicolumn{2}{|c|}{ High } & \multicolumn{2}{|c|}{ Low } & \multicolumn{2}{|c|}{ High } & \multicolumn{2}{|c|}{ Neutral } \\
\hline & $M$ & $S D$ & $M$ & $S D$ & $M$ & $S D$ & $M$ & $S D$ & $M$ & $S D$ \\
\hline $2 \mathrm{sec}$ & 1.86 & .90 & 1.69 & .90 & 1.48 & .78 & 1.67 & .84 & 1.57 & .74 \\
\hline $4 \mathrm{sec}$ & 3.65 & 1.29 & 3.48 & 1.36 & 3.51 & 1.42 & 3.79 & 1.61 & 3.46 & 1.36 \\
\hline $6 \mathrm{sec}$ & 5.20 & 1.81 & 4.95 & 1.73 & 5.24 & 2.28 & 4.88 & 1.90 & 4.89 & 1.84 \\
\hline
\end{tabular}


Table A3

Means (in Seconds) and Standard Deviations of the Untransformed Time Estimations for the Emotional and Neutral Slides-Interval Reproduction Method

\begin{tabular}{|c|c|c|c|c|c|c|c|c|c|c|}
\hline \multirow[b]{4}{*}{ Time } & \multicolumn{10}{|c|}{ Arousal } \\
\hline & \multicolumn{4}{|c|}{ Positive } & \multicolumn{4}{|c|}{ Negative } & & \\
\hline & \multicolumn{2}{|c|}{ Low } & \multicolumn{2}{|c|}{ High } & \multicolumn{2}{|c|}{ Low } & \multicolumn{2}{|c|}{ High } & \multicolumn{2}{|c|}{ Neutral } \\
\hline & $M$ & $S D$ & $M$ & $S D$ & $M$ & $S D$ & $M$ & $S D$ & $M$ & $S D$ \\
\hline$\overline{2 \mathrm{sec}}$ & 1.33 & .53 & 1.27 & .48 & 1.17 & .42 & 1.60 & .57 & 1.29 & .37 \\
\hline $4 \mathrm{sec}$ & 2.64 & .72 & 2.30 & .55 & 2.39 & .76 & 2.44 & .72 & 2.52 & .73 \\
\hline $6 \mathrm{sec}$ & 4.01 & 1.27 & 3.47 & 1.09 & 3.62 & 1.08 & 3.87 & 1.36 & 3.81 & 1.19 \\
\hline
\end{tabular}

(Manuscript received November 8, 1995;

revision accepted for publication August 20, 1996.) 